\section{Relationship between Regional Myocardial Blood Flow and Thallium-201 Distribution in the Presence of Coronary Artery Stenosis and Dipyridamole-induced Vasodilation}

Arthur E. Mays, Jr. and Frederick R. Cobb

Department of Medicine, Division of Cardiology, Duke University Medical Center, and the Veterans Administration Medical Center, Durham, North Carolina 27710

flow increases. During the dipyridamole infusion, the increases in phasic blood flow, the distributions of regional myocardial blood flow, and the relationships between thallium-201 localization and regional blood flow were comparable to values previously observed in exercising dogs with similar occlusions. These data provide basic validation that supports the use of intravenous dipyridamole and thallium-201 as an alternative to exercise stress and thallium-201 for evaluating the effects of coronary occlusive lesions on the distribution of regional myocardial blood flow.

\section{Introduction}

Thallium-201 is the radioisotope most used to assess myocardial perfusion during rest and exercise (1-3). Optimum evaluation of myocardial perfusion in patients with chest pain syndromes requires the injection of thallium-201 during dynamic exercise to end points of chest pain, electrocardiographic evidence of ischemic and/or predicted heart rate for age, and continual exercise for 30-60 s to allow myocardial uptake and exponential clearance of thallium-201 from the blood. The achievement of satisfactory exercise end points may be limited by poor physical condition or exercise effort, peripheral vascular disease, and/or musculoskeletal or neuromuscular diseases. In addition, adrenergic blocking agents may prevent the achievement of satisfactory heart rate end points.

Gould (4) described the potential role of dipyridamole as that of a pharmacologic coronary vasodilator, and of myocardial imaging as a way to noninvasively assess coronary stenoses in experimental animals; several investigators have used intravenous dipyridamole as an alternative stress to exercise in patients for effecting coronary vasodilation $(5,6)$. Dipyridamole is a potent, direct coronary vasodilator that, unlike exercise, increases myocardial blood flow with little or no change in myocardial oxygen demands (7). Although studies $(5,6)$ have reported that thallium-201 scintigraphy during intravenous dipyridamole infusion may be comparable to dynamic exercise in the diagnostic 
evaluation of subjects with coronary artery disease, the distribution of myocardial blood flow during critical coronary stenosis and vasodilation induced by dipyridamole has not been assessed directly. In addition, some reports have concluded that thallium201 activity in the heart may not accurately reflect the myocardial perfusion during coronary vasodilation that occurs without increased myocardial oxygen demands $(4,8,9)$.

This study was thus designed first to assess the regional distribution of myocardial blood flow during marked vasodilation induced by dipyridamole in the presence of severe stenosis and complete occlusion and, second, to examine the relationship between the regional distribution of thallium-201 and myocardial blood flow under these conditions. Studies were performed in chronically instrumented awake dogs to avoid the variables introduced by acute surgery.

\section{Methods}

10 adult mongrel dogs of either sex weighing $16-23 \mathrm{~kg}$ were anesthetized with an intravenous bolus of sodium thiamylal $(30-40 \mathrm{mg} / \mathrm{kg})$ and placed on a mechanical ventilator. A left thoracotomy was performed using sterile technique, and 3-mm-diam polyvinyl chloride heparin-filled catheters were introduced into the ascending aorta through the left internal mammary artery and into the left atrial cavity via the appendage. The proximal $1.5 \mathrm{~cm}$ of the circumflex branch of the left coronary artery was dissected free, and an electromagnetic flow probe (Howell Instruments, Camarillo, CA) was positioned around the vessel. An inflatable balloon occluder, constructed in our laboratory, was placed around the circumflex vessel distal to the flow probe. The catheters, occluder tubing, and flow probes were tunneled through the chest wall and placed in a subcutaneous pouch at the base of the neck. The thoracotomy incision was closed and the dogs were allowed to recover.

Studies were carried out 7-10 d postoperative, when the animals were active, fully recovered from surgery, and free from fever and anemia. The morning of the study, each dog received an intramuscular injection of $5 \mathrm{mg}$ morphine sulphate at least $2 \mathrm{~h}$ before measurements were made. The dogs were placed on a soft mat and allowed to lie quietly on their right side. The subcutaneous pouch was infiltrated with $1 \%$ lidocaine hydrochloride and the catheters and flow probe were exteriorized through a small skin incision. The aortic and left atrial pressure catheters were connected to transducers (P23Db; Statham Instruments, Inc., Oxnard, $\mathrm{CA}$ ) and the zero pressure reference was adjusted to the mid-chest level. Phasic and mean circumflex coronary flow were measured with a flowmeter (HMS 1000; Howell Instruments). A peripheral intravenous catheter was inserted for the administration of dipyridamole. The balloon occluder was connected to a hand-held 10-ml plastic syringe. After the instrumentation was connected, the laboratory lights were dimmed and the area was kept free of noise and extraneous activity. The animal was allowed to attain a basal state before data collection was begun. All data were recorded on an eight-channel direct-writing oscillograph (Model 7700; Hewlett-Packard Co., Palo Alto, CA).

The balloon occluder was inflated and the left circumflex coronary flow was totally occluded for $20 \mathrm{~s}$. After the occluder was deflated, circumflex blood flow increased four-fivefold in each preparation. After a return to control hemodynamics, regional myocardial blood flow was determined by injecting $1 \mathrm{ml}{ }^{95} \mathrm{Nb}$-radiolabeled microspheres into the left atrium and collecting reference blood sample. A continuous intra- venous infusion of dipyridamole (Boehringer Ingelheim, Ridgefield, CT) $56 \pm 28 \mu \mathrm{g} / \mathrm{kg}$ per min was started. After the left circumflex coronary flow increased to match the peak hyperemic value previously noted, the balloon occluder was partially inflated to reduced phasic blood flow to the control value. Restriction of left circumflex coronary inflow in this fashion corresponds to $\sim 90 \%$ stenosis (10). After $60 \mathrm{~s}$ of partial occlusion and stable blood flow, $0.5 \mathrm{mCi}^{201} \mathrm{Tl}$ (Mallinckrodt Inc., St. Louis, MO) and $1 \mathrm{ml}{ }^{46} \mathrm{Sc}$-labeled microspheres were injected as before. The partial occlusion was maintained for $5 \mathrm{~min}$ after isotope administration and the animals were then promptly anesthetized with sodium thiamylal $(30 \mathrm{mg} / \mathrm{kg})$ and fibrillated with 40 meq potassium chloride administered intravenously. Five animals were studied according to the preceding protocol (group 1); five additional dogs were studied in the same manner, but their left circumflex coronary artery inflow was completely occluded (group 2).

Immediately after sacrifice, the hearts were excised, rinsed with iced saline, packed in ice, and refrigerated for $2 \mathrm{~h}$ to firm them before sectioning. The atria, right ventricle, and large epicardial vessels were then dissected free and discarded. The left ventricle was sectioned into four transverse rings from base (ring 1) to apex (ring 4). Each ring was divided initially into seven anatomic regions that corresponded to the anterior papillary muscle, anterior free wall, anterior and posterior septum, posterior free wall, posterior papillary muscle, and lateral free wall. Each region was subdivided into four transmural layers from epicardium (layer 1) to endocardium (layer 4). The individual tissue samples were weighed and placed in separate plastic vials for later counting.

Regional myocardial blood flow was determined by injecting into the left atrium $9 \pm 1 \mu \mathrm{m}$ carbonized microspheres (Minnesota Mining and Manufacturing Co., St. Paul, MN) labeled with the $\gamma$-emitting radionuclides ${ }^{95} \mathrm{Nb}$ and ${ }^{46} \mathrm{Sc}$. Microspheres were obtained as $1.0 \mathrm{mCi}$ of each radionuclide in $10 \mathrm{ml}$ of $10 \%$ dextran. This stock solution was diluted further in $10 \%$ dextran so that $1 \mathrm{ml}$ contained $\sim 3 \times 10^{6}$ microspheres. The microsphere solutions were mixed before injection by alternate agitation in an ultrasonic bath and vortex agitator for at least $15 \mathrm{~min}$. Blood flow measurements were made by injecting $1 \mathrm{ml}$ of the microsphere suspension into the left atrial catheter over a 5-s interval. The catheter was flushed with $10 \mathrm{ml}$ of normal saline for $10 \mathrm{~s}$ more. A reference sample of arterial blood was collected from the aortic catheter at a constant rate with a withdrawal pump (Harvard Apparatus Co., Inc., The Ealing Corp., South Natick, MA). Collection began simultaneously with the microsphere injection and continued for $90 \mathrm{~s}$. The withdrawal rate of the pump was carefully calibrated both before and immediately after each study.

The $\gamma$-activity for each radionuclide that appeared in the reference blood and tissue samples was determined with a $\gamma$-spectrophotometer (model A 5912; Packard Instruments Co., Inc., United Technologies, Downers Grove, IL). Thallium-201 activity in each tissue sample was determined immediately after sectioning. The samples were held for $7 \mathrm{~d}$ to allow high-energy contaminant isotopes of thallium-201 to decay. Activity associated with the ${ }^{95} \mathrm{Nb}$ - and ${ }^{46} \mathrm{Sc}$-radionuclides was then assessed in the tissue and reference blood sample to determine myocardial blood flow. Counts were accumulated in predetermined energy range "windows" selected to maximize activity from a given isotope while minimizing spillover from the other isotopes used in the study. Total blood flow to each myocardial tissue sample $\left(Q_{\mathrm{m}}\right)$ in milliliters per minute was calculated by the formula $Q_{\mathrm{m}}=Q_{\mathrm{r}}\left(C_{\mathrm{m}} / C_{\mathrm{r}}\right)$, where $Q_{\mathrm{r}}$ is the reference blood flow (milliliters per minute), $C_{\mathrm{m}}$ is the count activity in the myocardial tissue sample, and $C_{\mathrm{r}}$ is the total count activity in the reference blood sample. Total myocardial tissue sample blood flow was divided by the corresponding tissue sample weight and expressed as milliliters 
Table I. Hemodynamic Measurements: Group 1

\begin{tabular}{|c|c|c|c|c|c|c|}
\hline \multirow[b]{2}{*}{ Intervention } & \multirow[b]{2}{*}{ Heart rate } & \multicolumn{3}{|c|}{ Aortic pressure } & \multirow{2}{*}{$\begin{array}{l}\text { Mean left atrial } \\
\text { pressure }\end{array}$} & \multirow{2}{*}{$\begin{array}{l}\text { Mean left circumflex } \\
\text { coronary flow }\end{array}$} \\
\hline & & Systolic & Diastolic & Mean & & \\
\hline Control & $74 \pm 6$ & $128 \pm 2$ & $76 \pm 4$ & $103 \pm 2$ & $4 \pm 1$ & $34.6 \pm 6.0$ \\
\hline Dipyridamole & $113 \pm 9 *$ & $107 \pm 6^{*}$ & $52 \pm 5^{*}$ & $80 \pm 6^{*}$ & $1 \pm 1^{*}$ & $37.3 \pm 4.8$ \\
\hline
\end{tabular}

All values are mean \pm SEM. * Values significantly different from control $(P<0.05)$.

per minute per gram of tissue. The endocardial/epicardial blood flow (endo/epi) ${ }^{1}$ ratio for a given anatomic region was the quotient of layer 4 blood flow and layer 1 blood flow. Transmural myocardial blood flow, mean flow, and the endo/epi ratio in the left circumflex and left anterior descending coronary arterial distributions were derived from the posterior papillary region and combined anterior and anterior papillary regions of rings one through three, respectively.

Heart rate, phasic and mean aortic pressure, left atrial pressure, and left circumflex coronary flow were measured from the graphic output obtained at the time of microsphere injection. These data were averaged over several respiratory cycles before microspheres were administered and again after the reference blood sample was collected.

Statistical comparison of the hemodynamic data and regional myocardial blood flow was based on the $t$ test for paired data. A curvilinear regression technique was used to fit data for each dog with first- and second-order models; data were analyzed before and after forcing the regression equation through the origin. An $F$ test was used to determine if inclusion of the second-order term significantly reduced the regression sum of squares (11). Computation of myocardial blood flow and statistical analysis were performed on a computer (1130 system 7; IBM Instruments, Inc., IBM Corp., Danbury, CT).

\section{Results}

Group 1. The mean hemodynamic data during partial restriction of left circumflex coronary artery inflow before and during dipyridamole infusion are listed in Table I. Compared with the control, dipyridamole infusion significantly increased heart rate and decreased aortic and left atrial pressures. In accordance with the experimental design, phasic left circumflex coronary flow did not change.

Mean and transmural myocardial blood flow in the region perfused by the left circumflex coronary artery during control conditions and during partial occlusion and dipyridamole infusion are illustrated in Fig. 1. Although mean flow was unchanged during dipyridamole infusion and partial occlusion, dipyridamole effected a redistribution of transmural blood flow in the partially occluded region; the higher subepicardial flow (layer 1) did not reach statistical significance; subendocardial flow (layer 4) decreased significantly. The redistribution of

1. Abbreviation used in this paper: endo/epi, endocardial/epicardial blood flow. transmural blood flow significantly decreased the endo/epi ratio. Blood flow in the regions supplied by the left anterior descending coronary artery increased approximately threefold in each transmural layer as compared with control values; the higher endo/epi ratio did not reach statistical significance (Fig. 2).

The relationship between the regional distribution of thallium-201 and myocardial blood flow during partial occlusion and dipyridamole infusion in each preparation is illustrated in Fig. 3. A marked heterogeneity in regional myocardial flow was noted; blood flow ranged from $0.5 \mathrm{ml} / \mathrm{min}$ per $\mathrm{g}$ to more than $5.0 \mathrm{ml} / \mathrm{min}$ per $\mathrm{g}$.

Group 2. Partial occlusion resulted in few data points with myocardial blood flow below $0.5 \mathrm{ml} / \mathrm{min}$ per $\mathrm{g}$. To define the relationship between thallium-201 distribution and coronary blood flow over a wider range of blood flow, including severe ischemia, a second group of animals was evaluated. The study protocol was the same as in group 1, but the left circumflex coronary artery was occluded totally rather than partially.

The mean hemodynamic data obtained in this group are listed in Table II. As in the previous group, dipyridamole infusion increased heart rate; the lower aortic and left atrial pressure measurements did not reach statistical significance. Myocardial

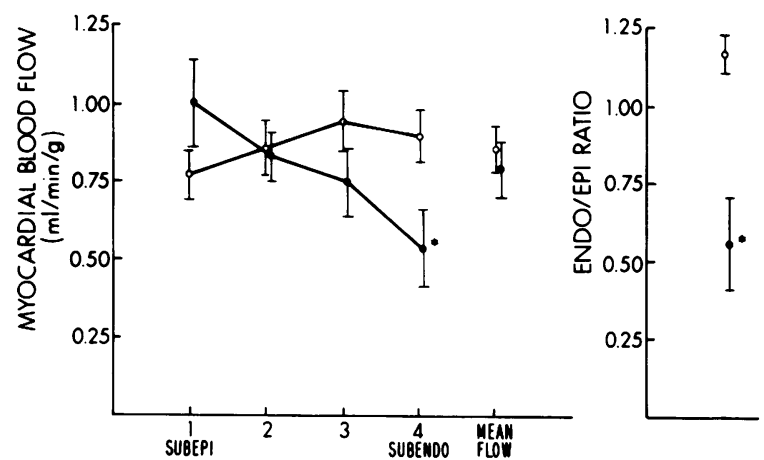

Figure 1. Transmural myocardial blood flow distribution from epicardium (layer 1) to endocardium (layer 4), mean transmural flow, and endo/epi ratio in the left circumflex coronary arterial circulation during control conditions (open circles) and during partial occlusion and dipyridamole infusion (closed circles). Vertical bars indicate \pm 1 SEM. Asterisks denote those values significantly different from the corresponding control value $(P<0.05)$. 


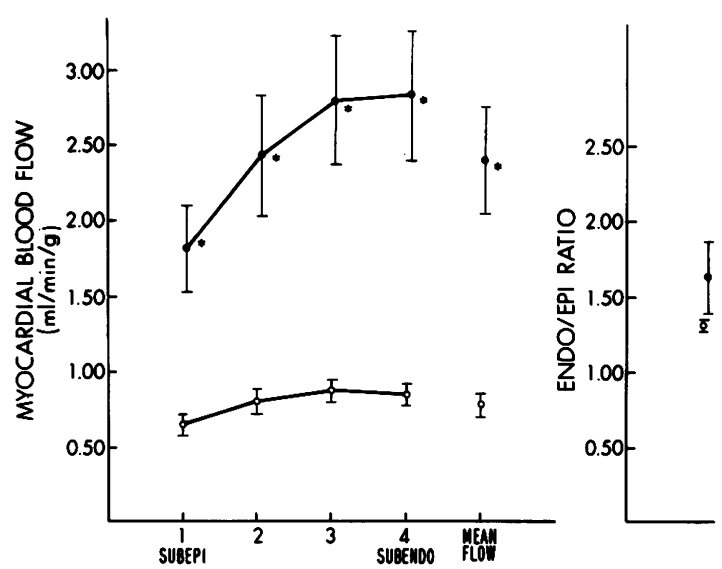

Figure 2. Transmural myocardial blood flow distribution from epicardium (layer 1) to endocardium (layer 4), mean transmural flow, and endo/epi ratio in the left anterior descending coronary arterial circulation during control conditions (open circles) and during partial occlusion of the circumflex artery and dipyridamole infusion (closed circles). Vertical bars indicate \pm 1 SEM. Asterisks denote those values significantly different from the corresponding control value $(P$ $<0.05$ ).

blood flow in the region supplied by the left circumflex coronary artery decreased markedly during the period of complete occlusion (Fig. 4). In the myocardial region unaffected by the total occlusion, the transmural distributions of myocardial blood flow, mean flow, and endo/epi ratio were comparable to those observed in group 1 preparations.

A curvilinear regression technique was used to fit the data from each dog with first- and second-order models. The $y$-axis intercepts were slightly positive when the data from both partial and total occlusions were used. Because the regression line should, logically, go through the origin, the individual analyses were performed before and after forcing the regression equation through the origin. The $r^{2}$ values for the analyses are listed in Table III. In each dog, the addition of a second-order term to the first-order model through the origin caused very small changes in $r^{2}$. The regression sum of squares, however, was significantly reduced in each $\operatorname{dog}(P<0.001)$ by including a second-order term, indicating that the relationship between thallium localization and myocardial blood flow during dipyridamole infusion was not precisely linear; there was a slight roll-off of thallium activity as blood flow increased. It should also be noted that the relationship was neither directly proportional nor 1:1; for a given increment in blood flow the thallium activity was always lower.

Previous studies from our laboratory compared the distribution of thallium-201 and myocardial blood flow in dogs exercising on a treadmill during total occlusion of the left circumflex coronary artery (12). When curvilinear regression analyses were performed on the exercise data from the previous study (12), $r^{2}$ values for first- and second-order models through the origin were comparable. However, the regression sum of squares was significantly reduced with a second-order model. The regression lines using the second-order model for each animal in the treadmill study (12) and for the animals in the present study subjected to dipyridamole are shown in Fig. 5; results from the animals subjected to total occlusion are illustrated, since data points are available over the same range as during treadmill exercise and total occlusion. Although the graphed data from several of the animals subjected to exercise appeared to have higher slopes than did data obtained during dipyridamole infusion, the regression lines in the two groups overlapped significantly; the coefficients of the first- and secondorder terms in the regression equations of the two groups were not significantly different. The data indicate that, over the range of blood flow studies, the relationship between thallium-201 and myocardial blood flow is very similar during exercise stress and dipyridamole infusion. There was also no significant difference between the coefficients for the first- and second-order

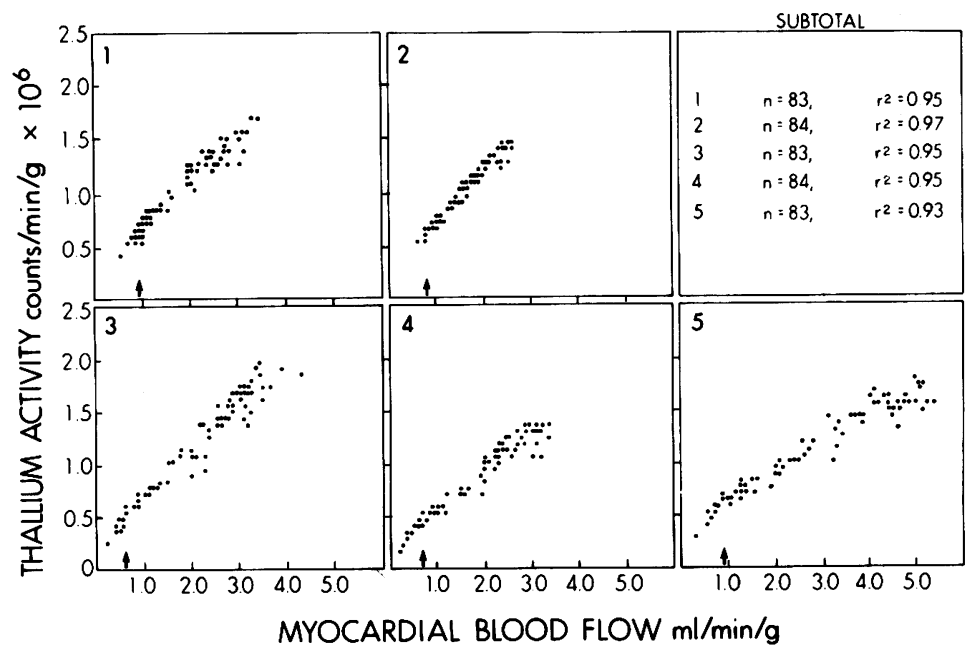

Figure 3. The relationship between thallium-201 activity and myocardial blood flow in five dogs during dipyridamole infusion and partial occlusion of the left circumflex coronary artery. Arrows denote resting myocardial blood flow. $n$, number of samples analyzed; $r$, correlation coefficient. 
Table II. Hemodynamic Measurements: Group 2

\begin{tabular}{|c|c|c|c|c|c|}
\hline \multirow[b]{2}{*}{ Intervention } & \multirow[b]{2}{*}{ Heart rate } & \multicolumn{3}{|c|}{ Aortic pressure } & \multirow{2}{*}{$\begin{array}{l}\text { Mean left } \\
\text { atrial } \\
\text { pressure }\end{array}$} \\
\hline & & Systolic & Diastolic & Mean & \\
\hline & beats/min & $m m H g$ & $m m H g$ & $m m H g$ & $m m H g$ \\
\hline Control & $65 \pm 4$ & $111 \pm 8$ & $71 \pm 4$ & $90 \pm 5$ & $4 \pm 1$ \\
\hline Dipyridamole & $119 \pm 10^{*}$ & $95 \pm 6$ & $55 \pm 6$ & $73 \pm 7$ & $3 \pm 1$ \\
\hline
\end{tabular}

All values are mean \pm SEM.

* Values significantly different from control $(P<0.05)$.

terms for the data obtained during dipyridamole infusion during total and subtotal occlusion.

Apparently there is variability between the regression curves in different animals. These differences may have been due to differences in the amount of radioactivity localized in the heart. Although the dosage administered was constant, animal weight did vary and thus the dosage per gram of body weight was not constant. Factors that may also have influenced the amount of myocardial localization include variability in the fraction of cardiac output delivered to the heart and variability in extraction fraction between animals.

\section{Discussion}

The relationship between the distribution of thallium-201 and myocardial blood flow during dipyridamole infusion was examined in two models that simulated the conditions and ranges of blood flow that may be encountered in subjects with coronary artery disease. One model was designed to examine the distribution of blood flow in the presence of a critical stenosis and marked vasodilation; in the second model vasodilation was induced during severe ischemia produced by total coronary occlusion. In both models, the left circumflex coronary flow was briefly occluded to effect marked vasodilation, and the hyperemic response was noted. Dipyridamole was then infused until mean coronary blood flow increased to match peak hyperemic values. In one model the balloon occluder was then inflated until left circumflex coronary blood flow was reduced to the preinfusion level. This procedure has been shown to effect $\sim 90 \%$ coronary artery stenosis (10). In the second model the vessels were totally occluded to produce regions of severe ischemia.

This study supports two major conclusions that have not been described previously. First, intravenous dipyridamole infusion in dosages that cause marked coronary vasodilation effects a distribution of regional myocardial blood flow that is comparable to, as previously reported by our laboratory, blood flow distribution during exercise and partial and complete coronary occlusion $(12,13)$ and during partial occlusion and ischemicinduced vasodilation (14). Second, regression analysis demonstrated that the relationship between the distribution of thallium-201 and myocardial blood flow during dipyridamole infusion was similar to that observed in animals subjected to treadmill exercise. Since thallium-201 is the isotope most used to noninvasively assess myocardial perfusion during exercise stress testing, these data provide basic validation that supports the use of dipyridamole infusion as an alternative stress to exercise for evaluating the effects of coronary occlusive lesions on the distribution of myocardial blood flow during conditions that require increased perfusion.

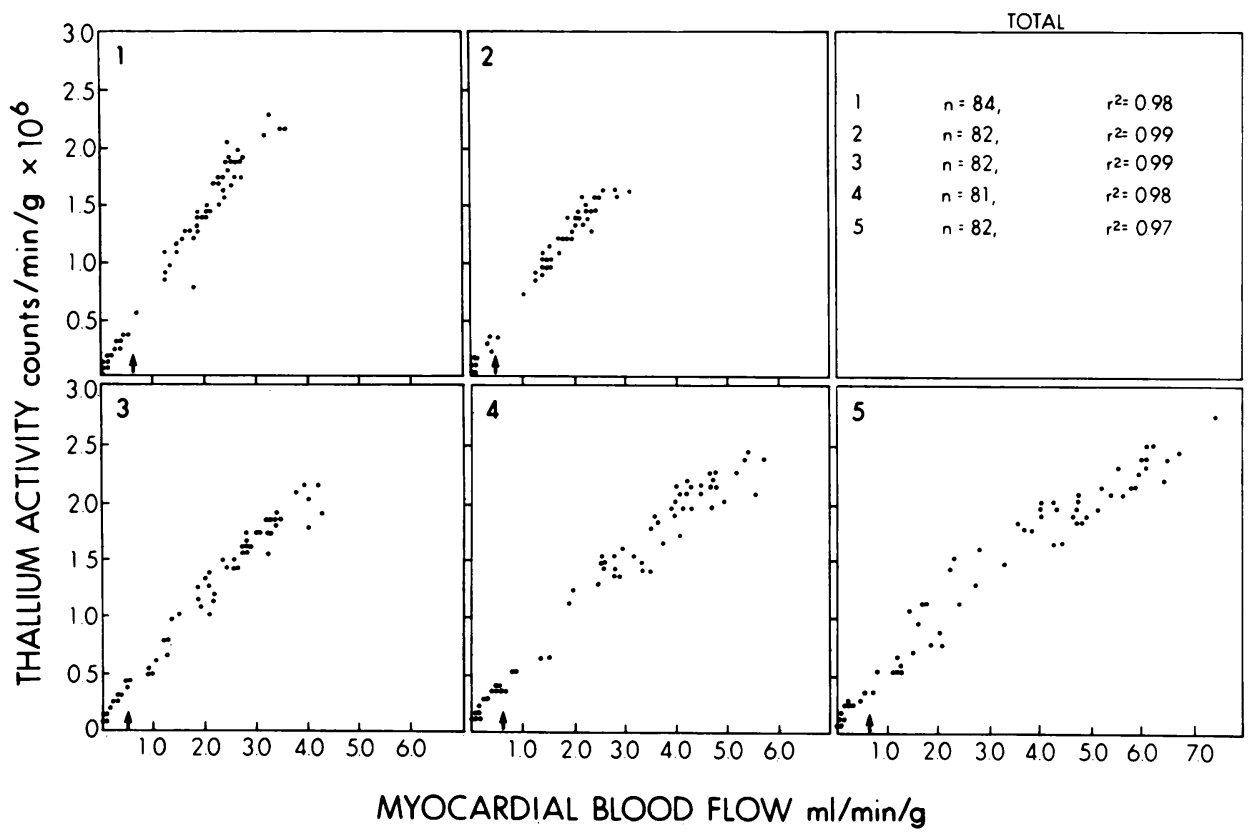

Figure 4. The relationship between thallium-201 activity and myocardial blood flow in five dogs during dipyridamole infusion and total occlusion of the left circumflex coronary artery. Arrows denote resting myocardial blood flow. $n$, number of samples analyzed; $r$, correlation coefficient. 
Table III. Curvilinear Regression Analyses Using First- and Second-Order Models Before and After Forcing Regression Equation through Origin

\begin{tabular}{|c|c|c|c|c|}
\hline & \multicolumn{2}{|l|}{ First order } & \multicolumn{2}{|c|}{ Second order } \\
\hline & $\begin{array}{l}\text { Normal } \\
\text { regression }\end{array}$ & $\begin{array}{l}\text { Forced } \\
\text { through } \\
\text { origin }\end{array}$ & $\begin{array}{l}\text { Normal } \\
\text { regression }\end{array}$ & $\begin{array}{l}\text { Forced } \\
\text { through } \\
\text { origin }\end{array}$ \\
\hline \multicolumn{5}{|c|}{ Subtotal occlusion } \\
\hline 1 & 0.95 & 0.79 & 0.95 & 0.95 \\
\hline 2 & 0.97 & 0.86 & 0.97 & 0.97 \\
\hline 3 & 0.95 & 0.91 & 0.96 & 0.95 \\
\hline 4 & 0.95 & 0.89 & 0.96 & 0.95 \\
\hline 5 & 0.95 & 0.74 & 0.96 & 0.93 \\
\hline \multicolumn{5}{|c|}{ Total occlusion } \\
\hline 1 & 0.98 & 0.98 & 0.98 & 0.98 \\
\hline 2 & 0.98 & 0.98 & 0.99 & 0.99 \\
\hline 3 & 0.98 & 0.97 & 0.99 & 0.99 \\
\hline 4 & 0.97 & 0.96 & 0.98 & 0.98 \\
\hline 5 & 0.95 & 0.93 & 0.97 & 0.97 \\
\hline
\end{tabular}

Data points are $r^{2}$ values. Normal regression refers to analyses performed without forcing the regression equation through the origin.

Previous studies have demonstrated that dipyridamole is a potent coronary vasodilator (7). Fan and McGregor (15) showed that increases in blood flow appear to result from a primary reduction in coronary vascular resistance, since coronary oxygen content increases markedly during dipyridamole infusion. In later studies, the investigators (16) concluded that the decrease in vascular resistance resulted from effects on intramuscular vessels, since resistance of the conductive epicardial vessels did not change. Degenring et al. (17) have proposed that the vasodilator effects of dipyridamole result from inhibition of myocardial cellular reuptake and capillary endothelial transport of

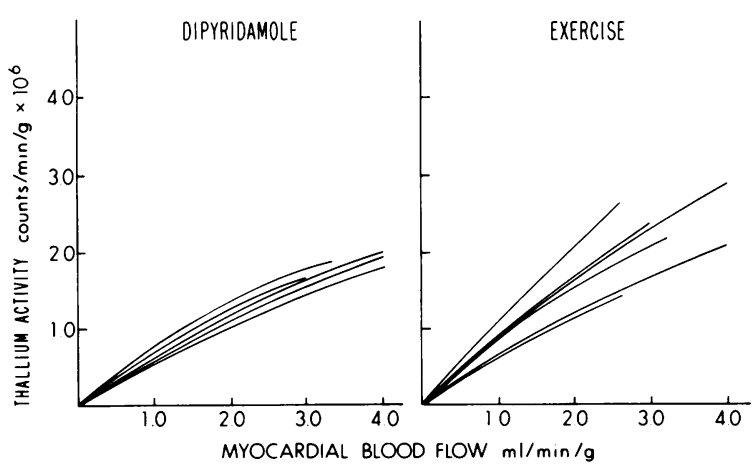

Figure 5. The relationship between thallium-201 activity (counts per minute per gram $\times 10^{6}$ ) and myocardial blood flow in animals subjected to total circumflex occlusion during dipyridamole infusion and treadmill exercise. The regression equations have been forced through the origin. endogenously produced adenosine. According to this hypothesis, adenosine increases in the interstitial fluid and effects vasodilation (18).

Previous studies from our laboratory and others have demonstrated that during vasodilation induced by intense exercise (19), and during the reactive hyperemic phase induced by transient ischemia (20) and by vasoactive drugs including adenosine (21) and chromar (22), myocardial blood flow increases fourto sixfold. These studies have indicated that during maximum or near-maximum vasodilation, blood flow is markedly increased in each layer and the endo/epi blood flow ratio usually remains near 1.0 .

Studies from our laboratory have demonstrated, however, that dosages of adenosine and dipyridamole that produce submaximal vasodilation result in greater endocardial than epicardial blood flow, causing an increase in the endo/epi ratio (23). In the present study, mean blood flow increased threefold and endocardial blood flow exceeded epicardial blood flow, resulting in an endo/epi ratio of 1.5 , which indicated that maximum increases in coronary blood flow were not present in all animals during the dipyridamole infusion. Dipyridamole resulted in a significant decrease in aortic pressure that reduced the maximum increase in blood flow. A degree of vasodilation, without a decrease in perfusion pressure, that is comparable to that during exercise would be expected to produce greater increases in blood flow. Note, however, that in samples with the highest blood flow values, blood flow measurements were 6 times mean base-line flow values (arrows in Figs. 3 and 4) in 6 of the 10 dogs and were 10 times mean base-line flow in dog 5 (Fig. 4). Thus, the distribution of thallium-201 was compared with a wide range of blood flow values in our study.

The effect of dipyridamole on the transmural distribution of myocardial blood flow in a region with restricted coronary perfusion has not been reported previously. The redistribution of regional myocardial blood flow in the partially occluded region in this study is comparable to that which our laboratory described earlier in animals with partial coronary artery stenosis and ischemia-induced vasodilation (14) and in exercising animals with partial occlusion (13). In awake dogs, Bache et al. (14) occluded the left circumflex coronary artery flow for $5 \mathrm{~s}$. The occluder was then deflated to allow coronary inflow to increase to preocclusion levels but to prevent the reactive hyperemic response. Regional myocardial blood flow determined during ischemiainduced vasodilation and limitation of inflow demonstrated an increase in subepicardial flow and decrease in subendocardial flow similar to that observed with dipyridamole.

There are several studies that suggest that if myocardial blood flow is increased without a proportional increase in myocardial oxygen requirements, disproportionately less thallium may localize in regions of augmented flow. Strauss et al. (8) compared the distribution of thallium-201 and microspheres during augmented blood flow induced by transient ischemia. They observed disproportionately less thallium-201 localization, compared with direct measurements of blood flow, when the 
agents were injected during the reactive hyperemic phase after transient ischemia. Transient ischemia initiates a reactive hyperemic response characterized first by a rapid increase in blood flow and then by a gradual return to control levels (24). The coronary arterial venous oxygen difference decreases during the reactive hyperemic phase, which indicates that blood flow exceeds myocardial oxygen needs (25). Thallium-localization during the hyperemic response may have been lower because it was influenced by the transient nonsteady state of the response and/or redistribution of thallium during the hyperemic phase, as well as by the nonmetabolic increase in flow induced by ischemia. Radioactive microspheres are trapped in the coronary vasculature during the first coronary passage and, thus, early in the reactive hyperemic phase. Weich et al. (9) reported a significant decrease in thallium-201 extraction for comparable coronary flows induced by vasodilators or metabolically stimulated by atrial pacing. They reasoned that thallium-201 uptake would be a more accurate measure of coronary blood flow when blood flow was increased in proportion to myocardial demands rather than in response to a primary vasodilator. Gould et al. (4) injected thallium-201 intravenously and technetium-99m albumin-labeled microspheres into the left atrium during dipyridamole infusion. Activity of each isotope in the heart, and thus myocardial perfusion, was assessed indirectly by external imaging. They observed that the ratio of myocardial to background counts of thallium-201 was $\sim 50 \%$ of that when the albumin microspheres were used. These studies did not examine the distribution of regional blood flow.

Previous studies have demonstrated a close linear relationship between direct measurements of regional myocardial blood flow and regional thallium-201 localization during acute ischemia (26). Earlier studies in our laboratory have shown that the initial localization of thallium-201 is closely related to myocardial blood flow during a wide range of blood flows produced by ischemia and exercise stress (12), and by acute ischemia and recent myocardial infarction (27). In the present study, curvilinear regression techniques were used to determine whether the relationship between thallium-201 and blood flow was best described by first- or second-order models. The data were also analyzed before and after the regression equation was forced through the origin. With the exception of values obtained during subtotal occlusion and when the regression equation was forced through the origin, the $r^{2}$ values for the first- and second-order models were not significantly different (Table III). The regression sum of squares, however, was significantly reduced in each dog by using a secondas compared with a first-order model through the origin, indicating that the localization of thallium-201 and myocardial blood flow during dipyridamole is not precisely linear but that it tends to roll-off very slightly as blood flow increases (Fig. 5).

Similar analysis of treadmill data from a previous study also demonstrated no significant difference in $r^{2}$ values when using a first- vs. a second-order model, but showed a reduced regression sum of squares with a second-order model and after forcing the data through the origin (Fig. 5). Thallium localization and myo- cardial blood flow were not directly proportional, since the increases in thallium activity were lower than the increases in blood flow. Net localization of thallium-201 in the heart is related not only to the extraction of thallium-201 but also to the ratio of coronary blood flow to cardiac output (28). If coronary blood flow and cardiac output increase to a degree similar to that which may occur during exercise, the net localization of thallium in the heart during exercise may not increase, even though coronary blood flow increases. Dipyridamole, on the other hand, increases coronary blood flow markedly with little or no change in cardiac output (7). Thus, a decrease in net thallium extraction during dipyridamole may be compensated for by greater thallium delivery to the myocardium.

The use of thallium to assess occlusive lesions depends on its ability to demonstrate the regional distribution of blood flow rather than to assess net blood flow to the entire ventricle. This study shows that the regional distribution of thallium during dipyridamole infusion closely follows the distribution of myocardial blood flow. Thallium activity in high blood flow regions was approximately three times that in areas of mildly reduced flow; differences were greater during severe ischemia. These differences should be readily detected by external imaging.

The effects of dipyridamole on coronary blood flow in man have been variable. Brown et al. (29) observed a mean increase of 2.8 and 3.8 times the control value in coronary sinus flow by thermodilution techniques during dipyridamole and dipyridamole-plus-handgrip stress, respectively, in three subjects with $<30 \%$ coronary artery stenosis; increases were lower in subjects with significant coronary stenosis. Strauer (30) observed a 4.8-times increase in coronary vascular reserve, which is defined as the ratio of coronary resistance at rest to resistance during maximum vasodilation with dipyridamole; measurements were made with argon clearance methods. These responses to dipyridamole are greater than the reported approximate threefold increases in coronary flow that occur in response to near-maximum bicycle exercise in normal subjects $(31,32)$.

The present study demonstrates that during intravenous dipyridamole infusion and critical stenosis, as well as during total occlusion of a major coronary artery, the distribution of regional blood flow and the relationships between thallium-201 localization and regional blood flow were comparable to values previously observed in exercising dogs with similar occlusions. These data provide basic validation that supports the use of dipyridamole infusion and thallium-201 as an alternative stress to exercise and thallium-201 for evaluating the effects of coronary stenosis on the regional distribution of myocardial blood flow during conditions requiring increased perfusion.

Note Added in Proof. In recent reports that appeared after this study was submitted, Beller et al. (1983. Circulation. 68:1328-1338) reported that in open-chest dogs, injection of thallium-201 during dipyridamole infusion was associated with a diminished uptake and delayed clearance of thallium-201 in regions of partial stenosis and with an increased uptake in more rapid clearance in normally perfused myocardium; Hintze and Vatner (1983. Circulation 68:1321-1327) demonstrated that dipyridamole infusion dilated large epicardial coronary arteries. 


\section{Acknowledgments}

We wish to acknowledge the valuable assistance of the following: Kirby Cooper and Eric Fields for surgical support; Robert Murdock and Marjorie Grubb for technical assistance; Philip McHale, Ph.D., for statistical analysis; J. Michael Taylor and the staff of the Durham Veterans Administration Medical Center Animal Care Facility; Donald Powell and staff of the Durham Veterans Administration Medical Center Media Service; and Cathie Collins for secretarial support.

This study is supported by grant HL18537 from the National Heart, Lung and Blood Institute and by the Research Service of the Durham Veterans Administration Medical Center.

\section{References}

1. Bailey, R. S., L. S. C. Griffith, J. Rouleau, H. W. Strauss, and B. Pitt. 1977. Thallium-201 myocardial perfusion imaging at rest and during exercise: comparative sensitivity to electrocardiography in coronary artery disease. Circulation. 55:79-87.

2. Ritchie, J. L., G. B. Trobaugh, G. W. Hamilton, K. L. Gould, K. A. Narahara, J. A. Murray, and D. L. Williams. 1977. Myocardial imaging with thallium-201 at rest and during exercise. Comparison with coronary arteriography and resting and stress electrocardiography. Circulation. 56:66-71.

3. Botvinick, E. H., M. R. Taradash, D. M. Shames, and W. W. Parmley. 1978. Thallium-201 myocardial perfusion scintigraphy for the clinical clarification of normal, abnormal and equivocal electrocardiographic stress tests. Am. J. Cardiol 41:43-51.

4. Gould, K. L. 1978. Noninvasive assessment of coronary stenosis by myocardial perfusion imaging during pharmacologic coronary vasodilatation. I. Physiologic basis and experimental validation. Am. J. Cardiol. 41:267-278.

5. Albro, P. C., K. L. Gould, R. J. Westcott, G. W. Hamilton, J. L. Ritchie, and D. L. Williams. 1978. Noninvasive assessment of coronary stenoses by myocardial imaging during pharmacologic coronary vasodilatation. III. Clinical trial. Am. J. Cardiol. 42:751-760.

6. Leppo, J., C. A. Boucher, R. D. Okada, J. B. Newell, H. W. Strauss, and G. M. Pohost. 1982. Serial thallium-201 myocardial imaging after dipyridamole infusion: diagnostic utility in detecting coronary stenoses and relationship to regional wall motion. Circulation. 66:649657.

7. West, J. W., S. Bellet, U. C. Manzoli, and O. F. Müller. 1962. Effects of persantin (RA8), a new coronary vasodilator, on coronary blood flow and cardiac dynamics in the dog. Circ. Res. 10:35-44.

8. Strauss, H. W., K. Harrison, J. K. Langan, E. Lebowitz, and B. Pitt. 1975. Thallium-201 for myocardial imaging: relation of thallium201 to regional myocardial perfusion. Circulation. 51:641-645.

9. Weich H. F., H. W. Strauss, and B. Pitt. 1977. The extraction of thallium-201 by the myocardium. Circulation. 56:188-191.

10. Gould, K. L., K. Libscomb, and G. W. Hamilton. 1974. Physiologic basis for assessing critical coronary stenosis: instantaneous flow responses and regional distribution during coronary hyperemia as measures of coronary flow reserve. Am. J. Cardiot. 33:87-94.

11. Pollard, J. H. 1977. Handbook of Numerical and Statistical Techniques. Cambridge University Press, New York. 281 pp.

12. Nielson, A. P., K. G. Morris, R. Murdock, F. P. Bruno, and F. R. Cobb. 1980. Linear relationship between the distribution of thallium-201 and blood flow in ischemic and nonischemic myocardium during exercise. Circulation. 61:797-801.

13. Ball, R. M., and R. J. Bache. 1976. Distribution of myocardial blood flow in the exercising dog with restricted coronary artery inflow. Circ. Res. 38:60-66.
14. Bache, R. J., F. R. Cobb, and J. C. Greenfield, Jr. 1974. Myocardial blood flow distribution during ischemia-induced coronary vasodilation in the unanesthetized dog. J. Clin. Invest. 54:1462-1472.

15. Fan, W. M., and M. McGregor. 1964. Effect of coronary vasodilator drugs on retrograde flow in areas of chronic myocardial ischemia. Circ. Res. 15:355-365.

16. Fan, W. M., and M. McGregor. 1968. Effect of nitroglycerin and dipyridamole on regional coronary resistance. Circ. Res. 22:649659.

17. Degenring, F. H., R. R. Cunnish, R. Rubio, and R. M. Berne. 1976. Effect of dipyridamole on myocardial adenosine metabolism and coronary flow in hypoxia and reactive hyperemia in the isolated perfused guinea pig heart. J. Mol. Cell Cardiol. 8:877-888.

18. Rubio, R., and R. M. Berne. 1969. Release of adenosine by the normal myocardium in dogs and its relationship to the regulation of coronary resistance. Circ. Res. 25:407-415.

19. Ball, R. M., R. J. Bache, F. R. Cobb, and J. C. Greenfield, Jr. 1975. regional myocardial blood flow during graded treadmill exercise in the dog. J. Clin. Invest. 55:43-49.

20. Cobb, F. R., R. J. Bache, F. Rivas, and J. C. Greenfield, Jr. 1976. Local effects of acute cellular injury on regional myocardial blood flow. J. Clin. Invest. 57:1359-1368.

21. Cobb, F. R., R. J. Bache, and J. C. Greenfield, Jr. 1974. Regional myocardial blood flow in awake dogs. J. Clin. Invest. 53:1618-1625.

22. Gross, G., and J. Warltier. 1981. Coronary steal in four models of single or multiple vessel obstruction in dogs. Am. J. Cardiol. 48:84-92.

23. Rembert, J. C., L. M. Boyd, W. P. Watkinson, and J. C. Greenfield, Jr. 1980. Effect of adenosine on transmural myocardial blood flow distribution in the awake dog. Am. J. Physiol. 239:H7-H13.

24. Olsson, R. A., and D. E. Gregg. 1965. Myocardial reactive hyperemia in the unanesthetized dog. Am. J. Physiol. 208:224-230.

25. Olsson, R. A., and D. E. Gregg. 1965. Metabolic responses during myocardial reactive hyperemia in the unanesthetized dog. Am. J. Physiol. 208:231-236.

26. Pohost, G. M., L. M. Zir, R. H. Moore, K. A. McKusick, T. E. Guiney, and G. A. Beller. 1977. Differentiation of transiently ischemic from infarcted myocardium by serial imaging after a single dose of thallium-201. Circulation. 55:294-302.

27. Chu, A., R. Murdock; and F. R. Cobb. 1982. Relation between regional distribution of thallium-201 and myocardial blood flow in normal, acutely ischemic and infarcted myocardium. Am. J. Cardiol. 50:1141-1144.

28. Adelstein, S. J., and A. Maseri. 1977. Radioindicators for the study of the heart: principles and applications. Prog. Cardiovasc. Dis. 20:3-17.

29. Brown, B. G., M. A. Josephson, R. B. Petersen, C. D. Pierce, M. Wong, H. S. Hecht, E. Bolson, and H. T. Dodge. 1981. Intravenous dipyridamole combined with isometric handgrip for near maximal acute increase in coronary flow in patients with coronary artery disease. $\mathrm{Am}$. J. Cardiol. 48:1077-1085.

30. Strauer, B. 1979. Ventricular function and coronary hemodynamics in hypertensive heart disease. Am. J. Cardiol. 44:999-1006.

31. Helmberg, S., W. Serzysko, and E. Varnauskas. 1971. Coronary circulation during heavy exercise in control subjects and patients with coronary heart disease. Acta Med. Scand. 190:465-480.

32. Heiss, H. W., J. Barmeyer, W. Wink, G. Hell, F. J. Cerny, J. Keul, and H. Reindell. 1976. Studies on the regulation of myocardial blood flow in man. I. Training effects on blood flow and metabolism of the healthy heart at rest and during standardized heavy exercise. Basic Res. Cardiol. 71:658-675. 